\title{
Economia brasileira e saúde: percepção de alunos de Saúde Pública sobre as contrarreformas e seus efeitos no SUS a partir de um processo de educação emancipatória
}

\author{
Aline Godoy VIEIRA ${ }^{(1)}$ \\ Áquilas Nogueira MENDES ${ }^{(1)}$ \\ Leonardo CARNUT $^{(1)}$ \\ ${ }^{(1)}$ Escola de Enfermagem, Universidade de São Paulo - USP, São Paulo, SP, Brasil.
}

Recebido: 28 jan 2019 Aceito: 10 fev 2019

Autor de correspondência: aline.godoy.to@gmail.com Conflito de interesses: Os autores declaram não haver nenhum interesse profissional ou pessoal que possa gerar conflito de interesses em relação a este manuscrito.

\section{Resumo}

O estudo sobre a "economia brasileira e a saúde" constitui atividade pioneira, tanto no ensino das graduações de Saúde Coletiva, quanto na Faculdade de Saúde Pública da Universidade de São Paulo - FSP-USP. O ensino dos conteúdos sobre economia faz-se pertinente porque, apesar de ser estruturante do processo de trabalho em saúde, existe pouca simpatia em relação a esses conteúdos entre graduandos. Supõe-se que à primeira vista, estudar economia não apareça no horizonte de expectativas de quem pretende se dedicar ao campo da saúde. Nessa perspectiva, é importante que uma disciplina de Economia Brasileira e Saúde propicie conhecimento entre a difícil trajetória que o Sistema Único de Saúde - SUS vem percorrendo desde sua implantação com a Constituição de 1988 e o padrão do capitalismo dependente do país nesses anos. O Brasil está há um bom tempo assistindo à adoção de políticas austeras por parte do Estado, com redução dos direitos sociais, especialmente na área da saúde, intensificando mecanismos de mercado e de privatização no seu interior. Desde 1990, nos tempos contemporâneos de supremacia do capital portador de juros (financeiro) no movimento do capitalismo, pode-se dizer que os anos foram marcados por contrarreformas que foram acentuando o desmonte do sistema de proteção social, concebido na Constituição de 1988, em direção aos interesses mercantis. O SUS não ficou imune a esse processo, à medida que o Estado brasileiro não parou de conceder incentivos à iniciativa privada, impondo riscos à saúde universal, com destaque para a introdução de modelos privatizantes de gestão e de subfinanciamento do sistema de saúde. Especificamente, as medidas implantadas no país, por meio do tripé macroeconômico ortodoxo - metas de inflação, superávit primário e câmbio flutuante -, adotadas pelo governo federal desde o governo de Fernando Henrique Cardoso (FHC) até o Governo Dilma Roussef, vêm envolvendo a redução do nosso sistema de proteção social. Entretanto, o entendimento desse complexo quadro econômico e política necessita de um tratamento histórico sobre como a saúde foi interagindo no padrão do desenvolvimento capitalista brasileiro, com destaque para os efeitos deletérios das contrarreformas adotadas pelos governos federais desde os anos 
1990. As disciplinas que apresentam o SUS aos graduandos não têm trazido a discussão sobre essas contradições, e sem a análise da economia política crítica marxista sobre a constituição e desmonte do sistema, é possível que esses futuros profissionais não tenham condições de fazerem boas análises das condições de produção da saúde. Além disso, considerando as tarefas e atribuições que assumirão, considera-se que o processo ensino-aprendizagem deva apoiar o desenvolvimento de maturidade científica e prática. Assim, apresenta-se um processo de docência com base em elementos de Educação Emancipatória e metodologias ativas, na produção de estudantes críticos. O trabalho analisa o resultado de um processo de ensino-aprendizagem de abordagem da economia política crítica marxista, a partir da percepção de alunos da disciplina de Economia Brasileira e Saúde, acerca dos efeitos das contrarreformas adotadas pelos governos federais nos 30 anos de existência do SUS. A disciplina consistiu em 11 encontros com duração de quatro horas cada, orientada para 25 alunos participantes do Curso de graduação de Saúde Pública da Faculdade de Saúde Pública da Universidade de São Paulo. Pedagogicamente, o Curso adotou elementos da Educação Emancipatória em que a produção de conhecimento se dá na relação com a realidade e suas contradições, bem como uma mescla de metodologias ativas. Trabalhou-se com a leitura de textos da economia política crítica marxista relacionados ao campo da Saúde Coletiva. Ao final de cada aula, os alunos responderam entrevistas semiestruturadas online sobre o tópico do dia. O tópico analisado neste trabalho referiu-se especificamente à percepção deles sobre como as contrarreformas adotadas pelos governos federais, a partir dos anos 1990 até a atualidade, provocou efeitos na saúde. Os discursos foram analisados através da análise de conteúdo clássica do tipo frequencial, cuja unidade de texto foram as proposições. As 36 proposições foram agrupadas em onze categorias. As categorias mais frequentes foram: (1) A metodologia foi boa devido ao tempo distribuído e assimilação dos conceitos, 31\%; (2) Perceberam o conteúdo das políticas cambiais, monetárias e fiscais, 28\%; e (3) Compreenderam as políticas de reforma, contrarreforma e mercado capitalista, 19\%". A percepção dos alunos sobre a relação entre as contrarreformas adotadas, suas políticas econômicas e os efeitos na saúde ampliou seu escopo de acordo com a perspectiva crítica desejada no âmbito da Disciplina. Além disso, o uso da Educação Emancipatória e das metodologias ativas de ensino-aprendizagem parece ter contribuído para que assimilassem conteúdo tão distante de seu campo específico de conhecimento. Compreendeuse que o processo de ensino-aprendizagem vivenciado favoreceu o aprendizado na perspectiva da economia política crítica da saúde. Considera-se importante que o pensamento do campo da Saúde Coletiva amplie sua capacidade da análise do contexto econômico e político a longo prazo. Assim, torna-se imperioso adotar o pensamento que privilegia a relação essencial entre o político e o econômico, entendendo que ambos fazem parte, em suas essências, das relações sociais constituídas no modo de produção capitalista, proporcionando, assim, um repertório intelectual que muito contribui para 
superar os limites analíticos do campo da Saúde Coletiva, particularmente de alunos de graduação, e especialmente nesse contexto que o momento contemporâneo exige. $O$ entendimento crítico desse processo histórico por meio dos futuros sanitaristas torna-se fundamental para lidarem com a difícil construção do SUS em tempos turbulentos do cenário contemporâneo econômico e político. Cabe destacar que os alunos chamaram muita atenção para a questão metodológica utilizada na no desenvolvimento da disciplina, permitindo a melhor compreensão do conteúdo proposto. Destaca-se a necessidade de coerência entre forma e conteúdo em que se buscou trabalhar nesse processo. A finalidade de produzir sanitaristas críticos depende de um processo crítico de docência que seja capaz de superar metodologias unidirecionais. É imperioso que futuros sanitaristas sejam apresentados à tarefa de analisar criticamente a determinação social dos processos de saúde. Apostar no uso de metodologias tradicionais de ensino não parece ser a solução mais adequada para um problema de tal magnitude: as contrarreformas e seus efeitos ao SUS.

Descritores: Economia; Crítica; Saúde Pública; Sistema Único de Saúde. 